\title{
PSYCHE.
}

\section{AN INTERESTING CASE OF MIMICRY.}

\author{
BY HERBERT OSBORN, COLUMBUS, OHIO.
}

Some time ago I received from $\mathrm{Mr}$. C. W. Mally, Assistant Entomologist, Cape Town, S. Africa, some specimens of a species of Homopteron which exhibits in a quite remarkable manner the adoption of a form and appearance which must serve it as a most efficient protection.

The insect itself Cephalelus infumatus is a little over half an inch long, of a brown color, and has a remarkably prolonged head which anteriorly tapers into a very large spine. This prolonged head is almost one half the total length of the insect. The body is slender and the wings terminate posteriorly somewhat abruptly but in such a manner that they fit very perfectly upon the stem of the plant which is its ordinary food.

The protective feature comes in from the fact that the aborted leaf sheaths on the stem of the plant form sharp spines occurring at intervals along the length of the stem and these are perfectly reproduced in the form and color of the insect. So close is the resemblance that when a number of the spines are mounted separately along side of the insects it is very difficult to distinguish them without the most careful scrutiny. When the speci- mens were first received I had looked them over some time before noticing that a number were not insects at all but simply spurs and had there not been one mounted with a fragment of stem along with an insect beside it I might have taken a much longer time to make the discovery. I have shown the set to a number of individuals who have taken quite a little time to make the same discovery.

This species was described many years ago by Percheron (Guerin. Mag. de Zool. II. IX. Pl. 48) and has been figured by Burmeister (Genera Insectorum Pl. 4.) and is mentioned in later works on African insects, but so far as I have been able to find there is no mention made of its foodplant or of the remarkable mimicry it presents. If collected without attention to the foodplant or noticing the peculiar spines which it resembles there would be no suspicion that such mimicry occurs.

According to Mr. Mally the insect lives on the rush, Dovea tectorum Masters, the spines of which are mimicked. I may mention that the stems are green while the aborted sheaths are dark brown. 

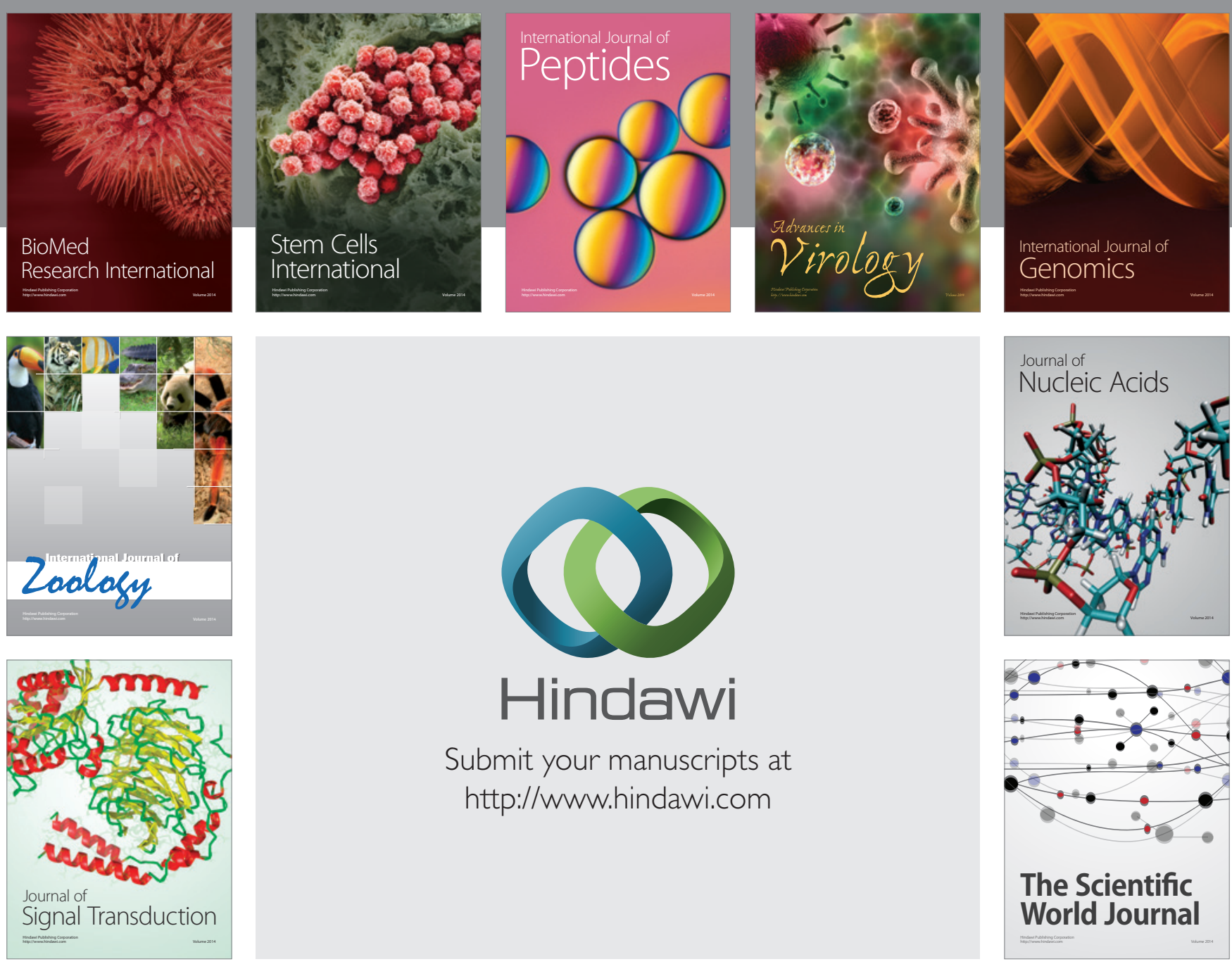

Submit your manuscripts at

http://www.hindawi.com
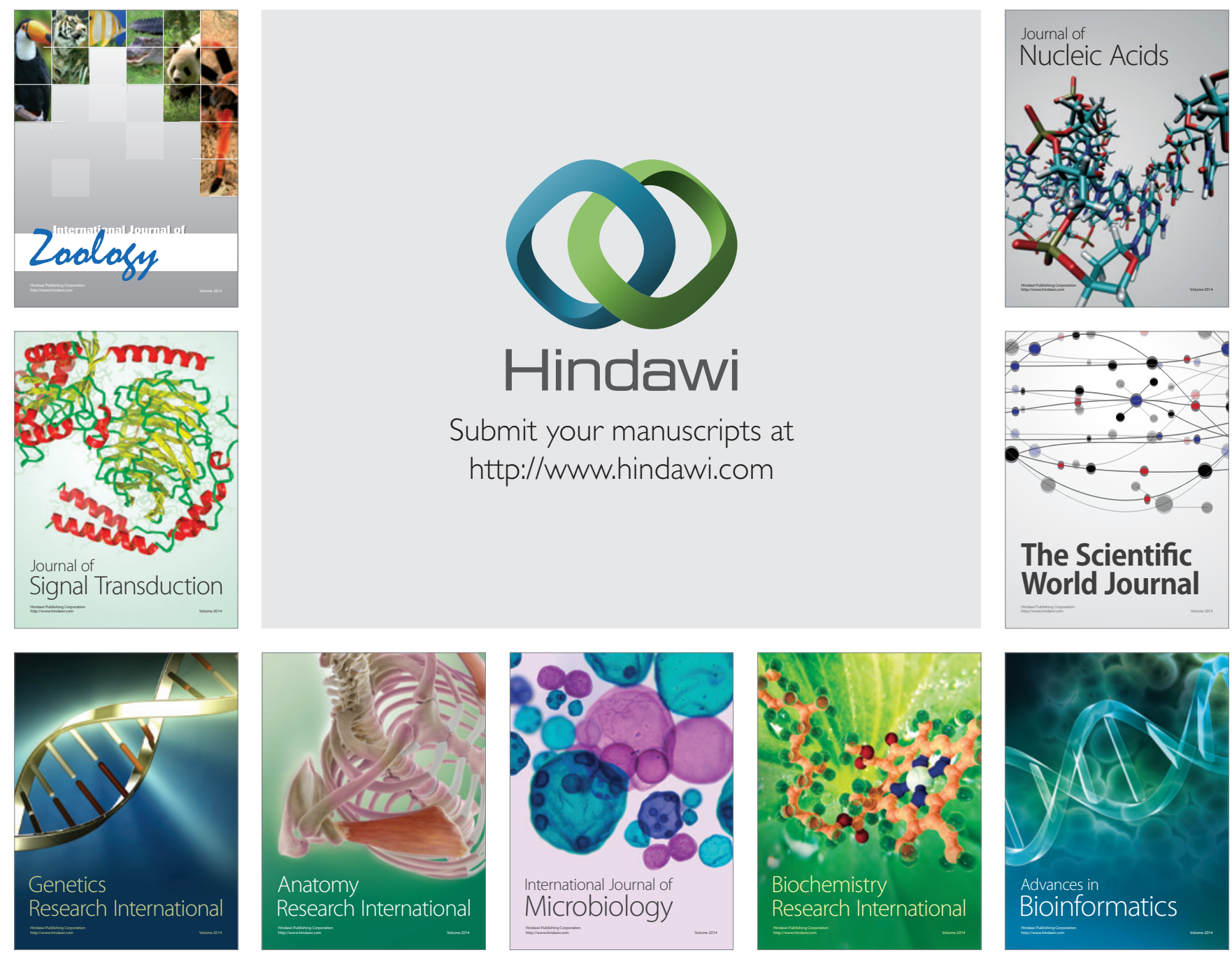

The Scientific World Journal
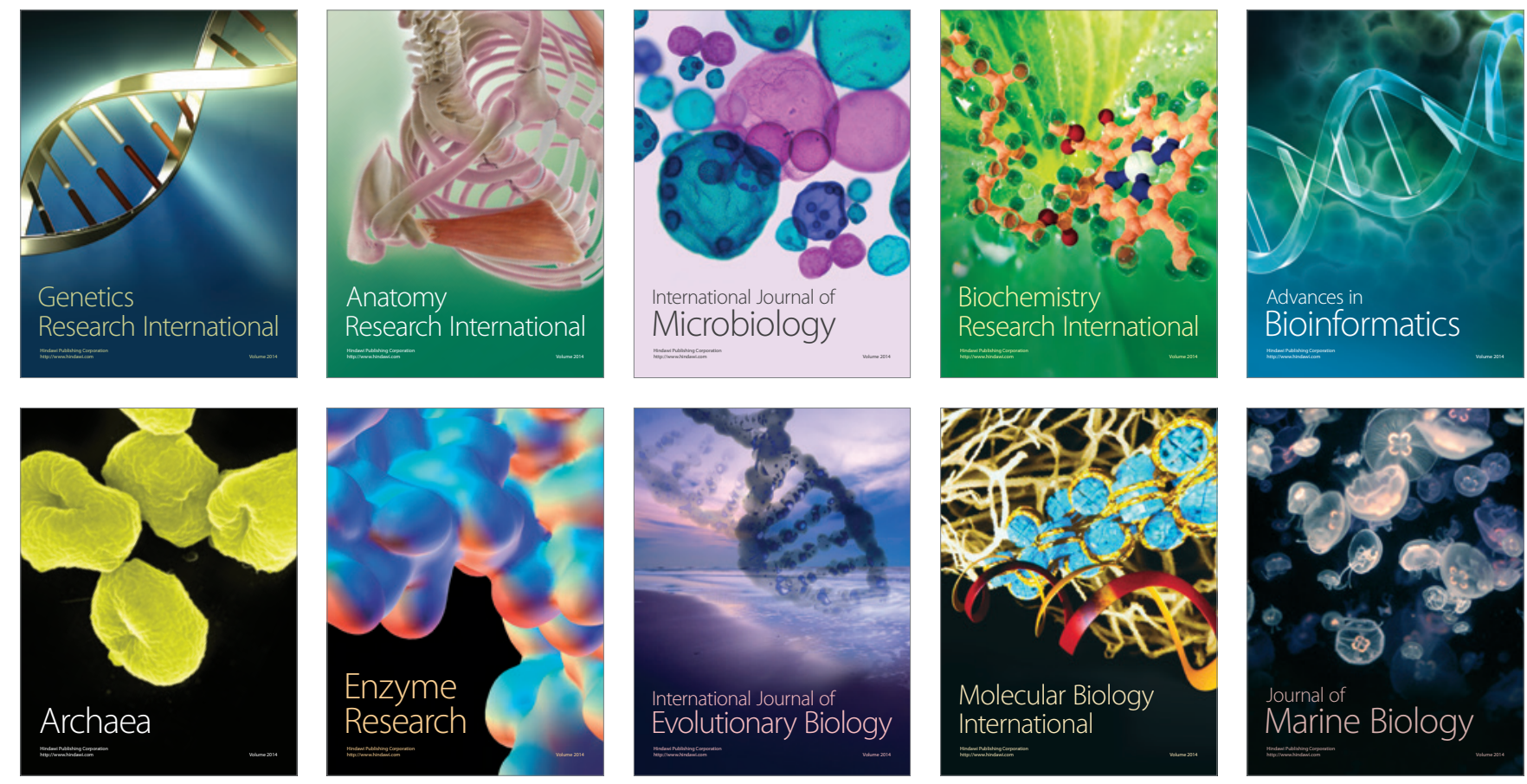